\title{
The Association of Haptoglobin Gene Variants and Retinopathy in Type 2 Diabetic Patients: A Meta-Analysis
}

\author{
Huiqun Wu, ${ }^{1,2}$ Huan Wu, ${ }^{1}$ Lili Shi, ${ }^{1}$ Xinlu Yuan, ${ }^{3}$ Ying Yin, ${ }^{1}$ Mingjie Yuan, ${ }^{1}$ Yushan Zhou, \\ Qianwen $\mathrm{Hu},{ }^{1}$ Kui Jiang, ${ }^{1}$ and Jiancheng Dong ${ }^{1}$ \\ ${ }^{1}$ Department of Medical Informatics, Medical School of Nantong University, Nantong 226001, China \\ ${ }^{2}$ Department of Biomedical Engineering, University of Southern California, Los Angeles, CA 90089, USA \\ ${ }^{3}$ Department of Endocrinology, Affiliated Hospital of Nantong University, Nantong 226001, China
}

Correspondence should be addressed to Kui Jiang; kuij@ntu.edu.cn

Received 25 February 2017; Accepted 23 May 2017; Published 3 July 2017

Academic Editor: Andrea Flex

Copyright (c) 2017 Huiqun $\mathrm{Wu}$ et al. This is an open access article distributed under the Creative Commons Attribution License, which permits unrestricted use, distribution, and reproduction in any medium, provided the original work is properly cited.

\begin{abstract}
Aims/Introduction. To collectively evaluate the association between haptoglobin ( $\mathrm{Hp}$ ) gene variants and diabetic retinopathy (DR) in patients with type 2 diabetes mellitus (T2DM). Methods. A comprehensive literature review was performed for eligible studies. After inclusion and exclusion selection as well as quality assessment, those studies meeting quality standards were included. In this study, diabetic patients with retinopathy were selected as the case group and those ones without DR were treated as the control group. The recessive model, allele model, additive model, heterozygote model, and homozygote model were utilized to investigate the association of three $\mathrm{Hp}$ gene variants and DR. Subgroup analysis on different severity of DR including nonproliferative diabetic retinopathy (NPDR) and proliferative diabetic retinopathy (PDR) was also conducted. Results. Six trials from different regions were finally included. A total of 1145 subjects containing 564 T2DM patients with retinopathy were included. The recessive model, allele model, additive model, and homozygote model results showed that $\mathrm{Hp}$ gene variants were not associated with DR, NPDR, and PDR. However, the heterozygote model indicated the association of Hp gene variants with DR. Conclusions. No association was found between the $\mathrm{Hp}$ gene variants and PDR and NPDR. More studies are required to verify these findings.
\end{abstract}

\section{Introduction}

Diabetes is a global health burden that affects populations' economic and health status. Due to the fact that diabetes is a system metabolic disorder, many organs and tissues will be affected and might be in dysfunction in the end. Management of diabetic complications has been a worldwide research of interest due to its clinical relevance and importance [1-3]. Vascular complications from diabetic complications such as nephropathy, retinopathy, and cardiovascular disease cause serious morbidity in patients with type 2 diabetes mellitus (T2DM) [4]. Diabetic retinopathy (DR) is one of the serious microvascular complications of T2DM patients and will finally cause blindness if not controlled effectively. As shown in recent epidemiologic studies, the prevalence of DR accompanied with T2DM is decreasing $[5,6]$.

Traditional measures to detect those microvascular complications mostly relied on imaging techniques. A digital fundus camera is such a device that could be utilized to record retinal blood vessels, the images of which are further assessed by ophthalmologists qualitatively. Besides biomarkers at the observable tissue level, some biomarkers at the molecular level are probably involved in the progression of above-mentioned microvascular complications. Heritability estimates for DR 


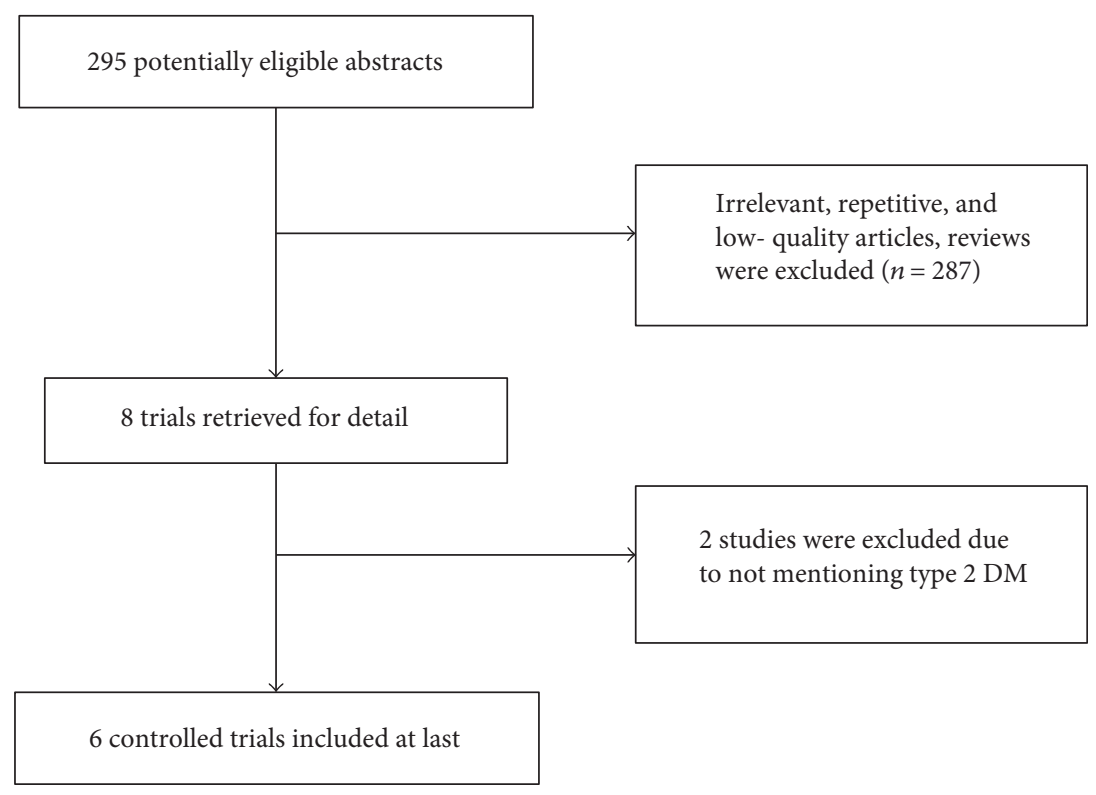

FIgURE 1: Flow chart of study selection.

range from 25 to $50 \%$, and the same degree of DR has been found in a cohort of identical twins with diabetes, suggesting that genetic variation is associated with DR. Haptoglobin (Hp) gene (rs137853233) is one of such candidate genes and is encoded by a single gene on chromosome 16. Hp gene has been discovered in human serum since 60 years ago, and the genetic mutation could be identified using SNP genotype data [7]. There are two common alleles for $\mathrm{Hp}$ which likely arose from a duplication event involving exons 3 and 4, usually denoted as $\mathrm{Hp} 1$ (containing 5 exons) and $\mathrm{Hp} 2$ (containing 7 exons) correspondingly. The most common type of allele variation consists of a major allele $(\mathrm{M})$ and a minor allele (m); the $\mathrm{Hp}$ phenotype variants can be a major allele homozygote (Hp1-1), a heterozygote (Hp2-1), or a minor allele homozygote (Hp2-2). Hp could form stable complexes with plasma-free hemoglobin $(\mathrm{Hb})$, as a result, blocking $\mathrm{Hb}$-induced oxidative damage. The binding of $\mathrm{Hp}$ to apolipoprotein A1 (ApoA1) has also been reported to be related to the T2DM-associated cardiovascular disease [8]. Hp protein also facilitates the removal of $\mathrm{Hb}$ from the extravascular compartment via the CD163 macrophage scavenger receptor. Unlike $\mathrm{Hp} 1-1$ and $\mathrm{Hp} 2-1$, Hp2-2 exists as large circular polymers, having decreased binding affinity for free hemoglobin, and has been associated with biomarkers of oxidant stress andiron delocalization. Several longitudinal studies have recently demonstrated that $\mathrm{Hp}$ gene variants might be an independent risk factor for different kinds of diabetes complications such as diabetic retinopathy, cardiovascular disease, and nephropathy, but with the discrepancy in their findings [9-12]. Therefore, in this study, we conducted a metaanalysis to summarize the results by using a recessive model, allele model, additive model, heterozygote model, and homozygote model to investigate the association of Hp gene variants and DR.

\section{Materials and Methods}

2.1. Search Strategy. In the research, a comprehensive literature review was performed on four electronic databases: PubMed (National Center for Biotechnology Information), ISI (Web of Science), Embase, and CNKI (China National Knowledge Infrastructure), and the related studies published in English or Chinese before January 2017.While conducting the searches in the databases, no restrictions were imposed for time and language. Two subsets of citations were enhanced, namely, an indexing DR or diabetes, the other indexing $\mathrm{Hp}$. For developing these subsets of citations, we used a combination of subject headings and text terms used in medical literature. Search terms used were as follows: (i) diabetic retinopathy, DR, diabetes without retinopathy, DWR, proliferative diabetic retinopathy, $\mathrm{PDR}$, non-proliferative diabetic retinopathy, NPDR, metabolic syndrome, diabetic complication, diabetes, diabe*, glycuresis; (ii) haptoglobin, $\mathrm{Hp}, \mathrm{Hp}^{*}$, gene, genetic, Hp1-1, Hp1-2, Hp2-1, Hp2-2; (iii) incidence, mortality, epidemiologic studies; and (iv) photography, photomicrography, photo\$, image\$, retinopathy, fundus. We combined the terms to generate a subset of citations that address the objective of our research study. We also hand searched reference lists of relevant articles for eligible studies. We examined the reference lists of all known primary and review articles to identify additional articles not captured by the electronic searches. The detailed search strategy is available from the authors. Two reviewers ( $\mathrm{Wu}$ and $\mathrm{Wu}$ ) independently examined the electronic searches and obtained full reports of all citations that were likely to meet the predefined selection criteria. Disagreements were resolved by consensus after discussion with a third reviewer (Yin).

2.2. Inclusion and Exclusion Criteria. The inclusion criteria were as follows: (i) case-control or cohort studies published about the association of $\mathrm{Hp}$ gene variants and $\mathrm{DR}$ 


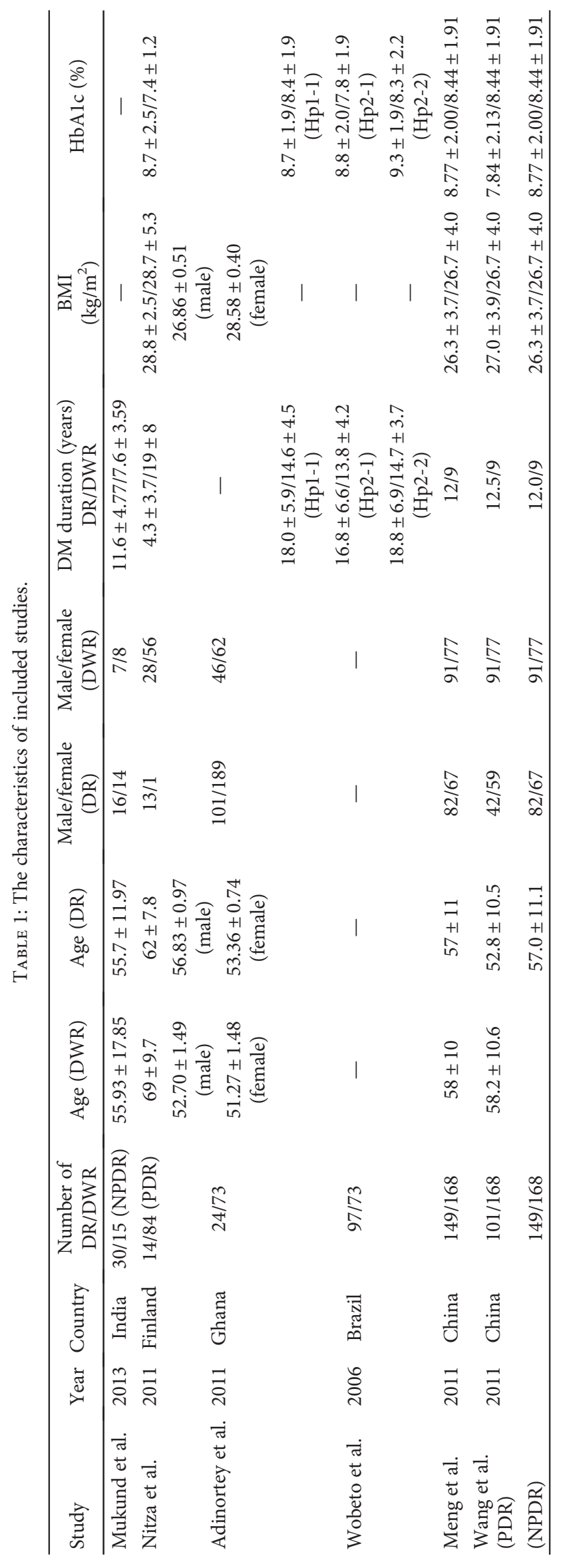


TABLE 2: Hp allele frequencies of cases and controls.

\begin{tabular}{|c|c|c|c|c|c|c|}
\hline \multirow{3}{*}{ Study } & \multicolumn{3}{|c|}{ DR } & \multicolumn{3}{|c|}{ DWR } \\
\hline & $\mathrm{CC}$ & $\mathrm{CT}$ & $\mathrm{TT}$ & $\mathrm{CC}$ & $\mathrm{CT}$ & TT \\
\hline & HP1-1 (\%) & HP2-1 (\%) & HP2-2 (\%) & HP1-1 (\%) & HP2-1 (\%) & HP2-2 (\%) \\
\hline Mukund et al. & $0(0)$ & $7(23.3)$ & $23(76.7)$ & $0(0)$ & $9(60.0)$ & $6(40.0)$ \\
\hline Nitza et al. & $4(28.6)$ & $5(35.7)$ & $5(35.7)$ & $19(22.6)$ & $23(27.4)$ & $42(50.0)$ \\
\hline Adinortey et al. & $4(16.7)$ & $6(25.0)$ & $14(58.3)$ & $2(3.7)$ & $0(0)$ & $52(96.3)$ \\
\hline Wobeto et al. & $4(5.2)$ & $47(61.0)$ & $26(33.8)$ & $17(23.3)$ & $36(49.3)$ & $20(27.4)$ \\
\hline Meng et al. & $2(1.4)$ & $82(55.0)$ & $65(43.6)$ & $3(1.8)$ & $78(46.7)$ & $86(51.5)$ \\
\hline Wang et al. (PDR) & $4(4.0)$ & 45 (44.6) & $52(51.4)$ & $3(1.8)$ & $86(51.5)$ & $78(46.7)$ \\
\hline (NPDR) & $2(1.4)$ & $65(43.6)$ & $82(55.0)$ & $3(1.8)$ & $86(51.5)$ & $78(46.7)$ \\
\hline
\end{tabular}

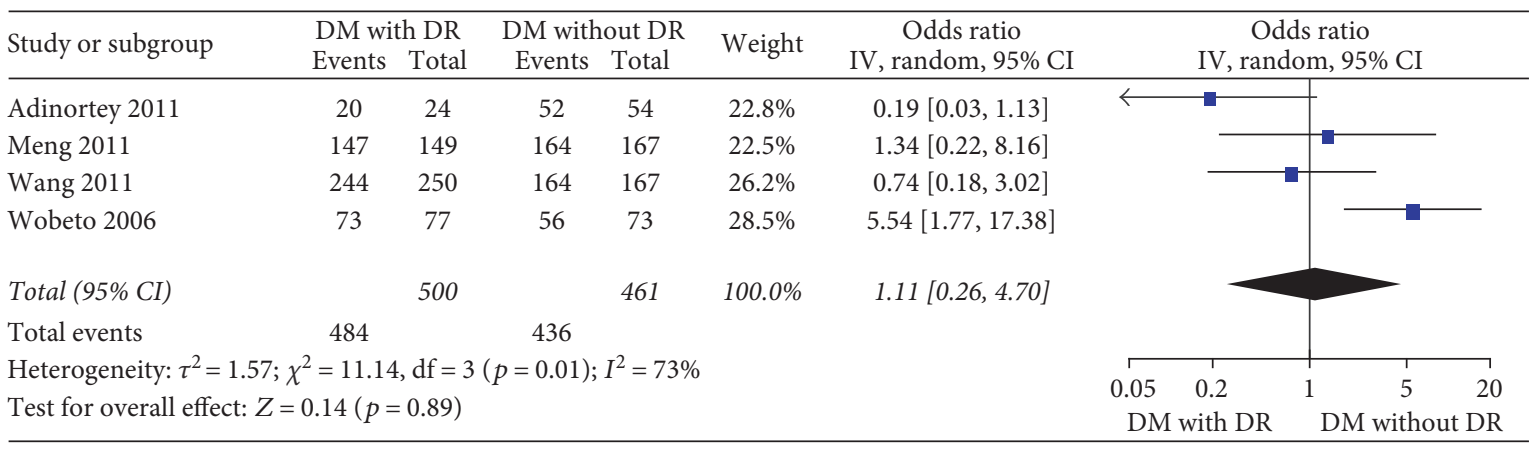

FIGURE 2: Forest plot for meta analysis comparing DR with DWR in dominant model (TT + CT versus CC).

in patients with the T2DM disease. (ii) Determination of DR was made by ophthalmoscope examination or fundus photography. (iii) Adequate information about the $\mathrm{Hp}$ genotype and allele were available. (iv) The language was written in English or Chinese.

The exclusion criteria were as follows: (i) insufficient data in frequencies of Hp genotype and allele, (ii) insufficient information about baseline characteristics of participants, (iii) literature reporting language other than English and Chinese, and (iv) patients diagnosed with T1DM other than T2DM.

2.3. Data Extraction and Analysis. In this study, those studies meeting the quality standards were included. The quality of the included studies was assessed by their risk of bias, directness, consistency of results, precision, publication bias, the magnitude of the effect, and so forth. In each of the included studies, three individual researchers ( $\mathrm{Wu}, \mathrm{Wu}$, and Yuan) independently extracted the raw data associated with the values of $\mathrm{Hp}$ gene variants, DR numbers, total study numbers, ages, sex, and other factors. In instances where the raw data could not be extracted or calculated, we obtained the same by contacting the authors of these manuscripts. The recessive model, allele model, additive model, heterozygote model, and homozygote model were utilized to investigate the association of $\mathrm{Hp}$ gene variants and DR. For improving the accuracy of these tests, subgroup analyses were used to identify the test-related or other factors responsible for heterogeneity. In this study, RevMan (version: 5.2) was used to perform meta-analysis. Odds ratio (OR) and its $95 \%$ confidence interval (CI) were calculated for statistical analysis. Heterogeneity was established using chi-square and quantified by $I^{2}$. In general, intergroup heterogeneity was evaluated by inconsistency index $\left(I^{2}\right)$ and heterogeneity. While the heterogeneity value was less than 0.1 , pooled OR was estimated by using a random effect model or otherwise using a fix effect model. Sensitivity analyses were performed by omitting each study to identify possible study contributing to the heterogeneity. A two-sided value which is less than 0.05 means statistically significant. Funnel plots were utilized for investigating publication and other biases in meta-analysis.

\section{Results}

The literature search yielded 295 references, six articles [13-18] out of which were eligible for inclusion finally. Figure 1 outlines the study selection.

3.1. Summary Characteristics of Included Studies. A total of six trials were retrieved for detail data extraction (Table 1). The six studies from different regions including India, Finland, Ghana, China, and Brazil were finally included for this analysis. A total of 1145 subjects includes 564 type 2 DM patients accompanied with retinopathy. All studies met inclusion and exclusion criteria. The average age of the included population was comparable (the elders ranged from 51.27 to 69 years old). Hp allele frequencies of cases and controls are shown in Table 2. Meta-analysis was performed on all these studies after adjusting for different sorts of risk factors. 


\begin{tabular}{|c|c|c|c|c|c|c|c|c|c|}
\hline \multirow{3}{*}{$\begin{array}{l}\text { Study or subgroup } \\
\text { Adinortey } 2011\end{array}$} & \multicolumn{2}{|c|}{ DM with DR } & \multicolumn{2}{|c|}{ DM without DR } & \multirow{2}{*}{ Weight } & \multirow{2}{*}{$\begin{array}{c}\text { Odds ratio } \\
\mathrm{IV} \text {, random, } 95 \% \mathrm{CI}\end{array}$} & \multirow{2}{*}{\multicolumn{3}{|c|}{$\begin{array}{l}\text { Odds ratio } \\
\text { IV, random, } 95 \% \mathrm{CI}\end{array}$}} \\
\hline & Events & Total & Events & Total & & & & & \\
\hline & 34 & 48 & 104 & 108 & $14.9 \%$ & $0.09[0.03,0.30]$ & & & \\
\hline Meng 2011 & 212 & 298 & 250 & 334 & $28.8 \%$ & $0.83[0.58,1.18]$ & & & \\
\hline Wang 2011 & 378 & 500 & 242 & 334 & $29.3 \%$ & $1.18[0.86,1.61]$ & & 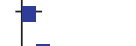 & \\
\hline Wobeto 2006 & 99 & 154 & 76 & 146 & $27.0 \%$ & $1.66[1.04,2.63]$ & & - & \\
\hline Total (95\% CI) & & 1000 & & 922 & $100.0 \%$ & $0.80[0.43,1.49]$ & & & \\
\hline Total events & 723 & & 672 & & & & & & \\
\hline \multirow{2}{*}{\multicolumn{6}{|c|}{$\begin{array}{l}\text { Heterogeneity: } \tau^{2}=0.32 ; \chi^{2}=22.22, \mathrm{df}=3(p<0.0001) ; I^{2}=86 \% \\
\text { Test for overall effect: } Z=0.70(p=0.48)\end{array}$}} & & & 10 & 100 \\
\hline & & & & & & \multicolumn{2}{|r|}{$\begin{array}{c}0.01 \quad 0.1 \\
\text { DM with DR }\end{array}$} & DM with & $\mathrm{DR}$ \\
\hline
\end{tabular}

FIgURE 3: Forest plot for meta analysis comparing DR with DWR in allele model (T versus C).

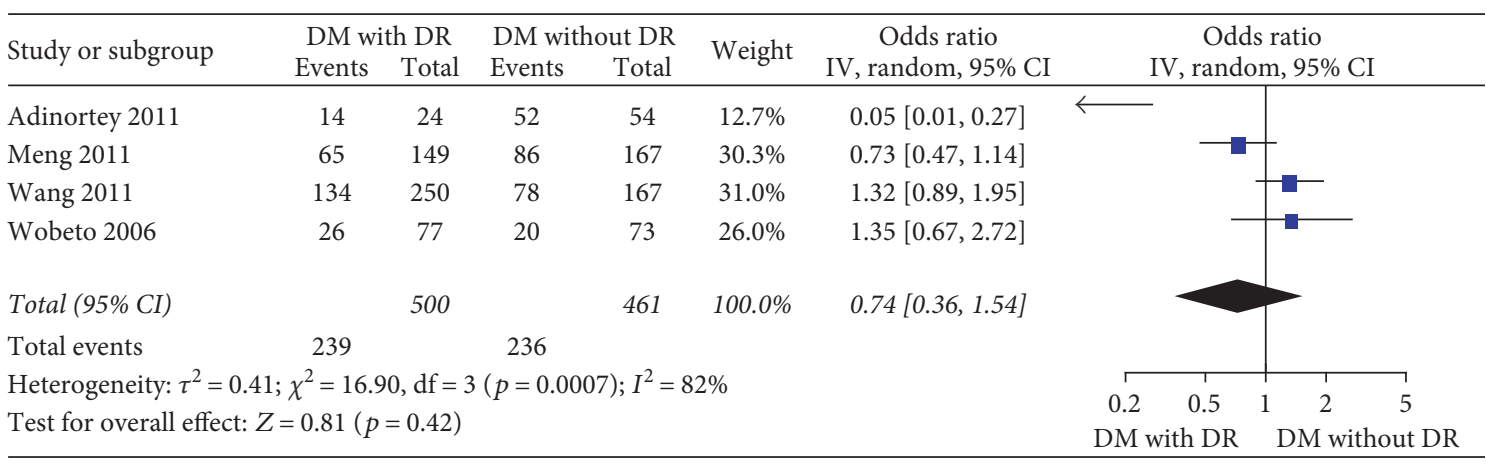

FIGURE 4: Forest plot for meta analysis comparing DR with DWR in recessive model (TT versus CT $+\mathrm{CC}$ ).

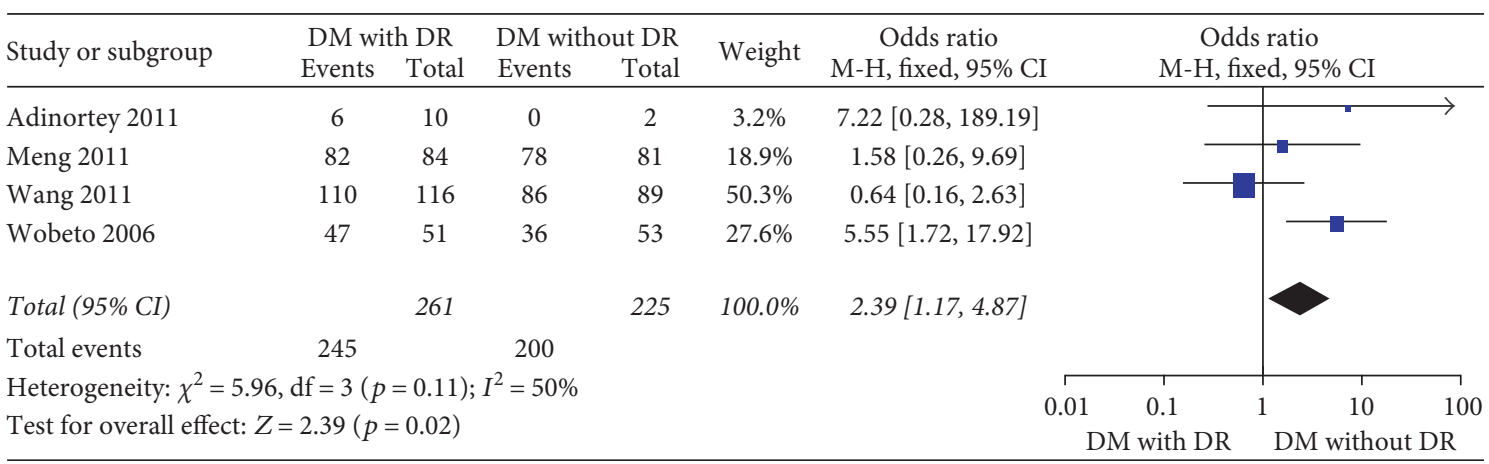

FIGURE 5: Forest plot for meta analysis comparing DR with DWR in heterozygote model (TC versus CC).

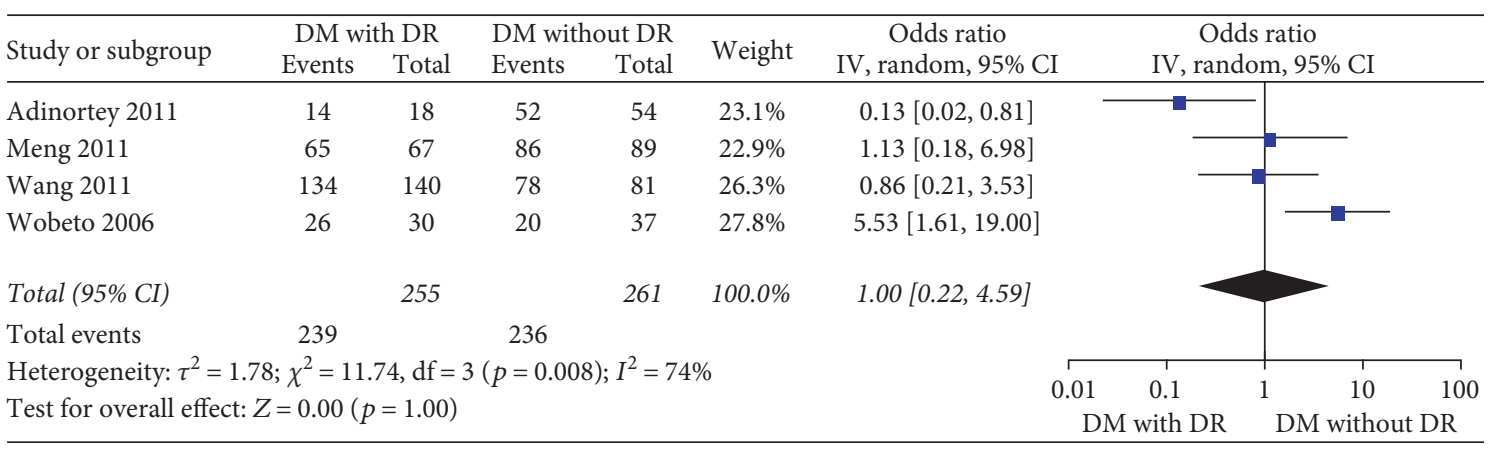

FIGURE 6: Forest plot for meta analysis comparing DR with DWR in homozygous model (TT versus CC). 


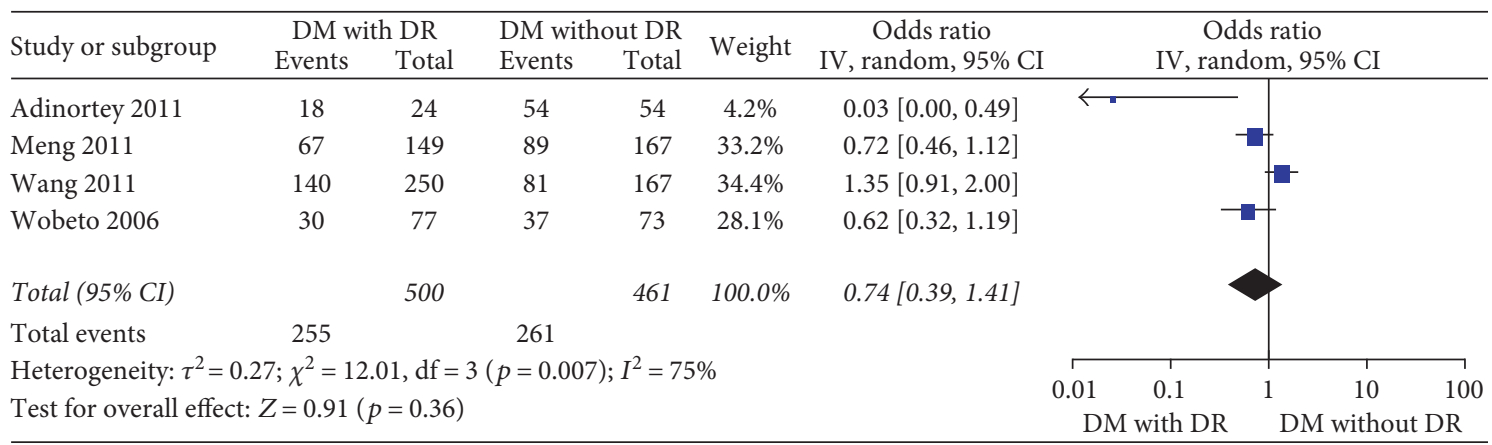

Figure 7: Forest plot for meta analysis comparing DR with DWR in additive model (TT + CC versus CT).

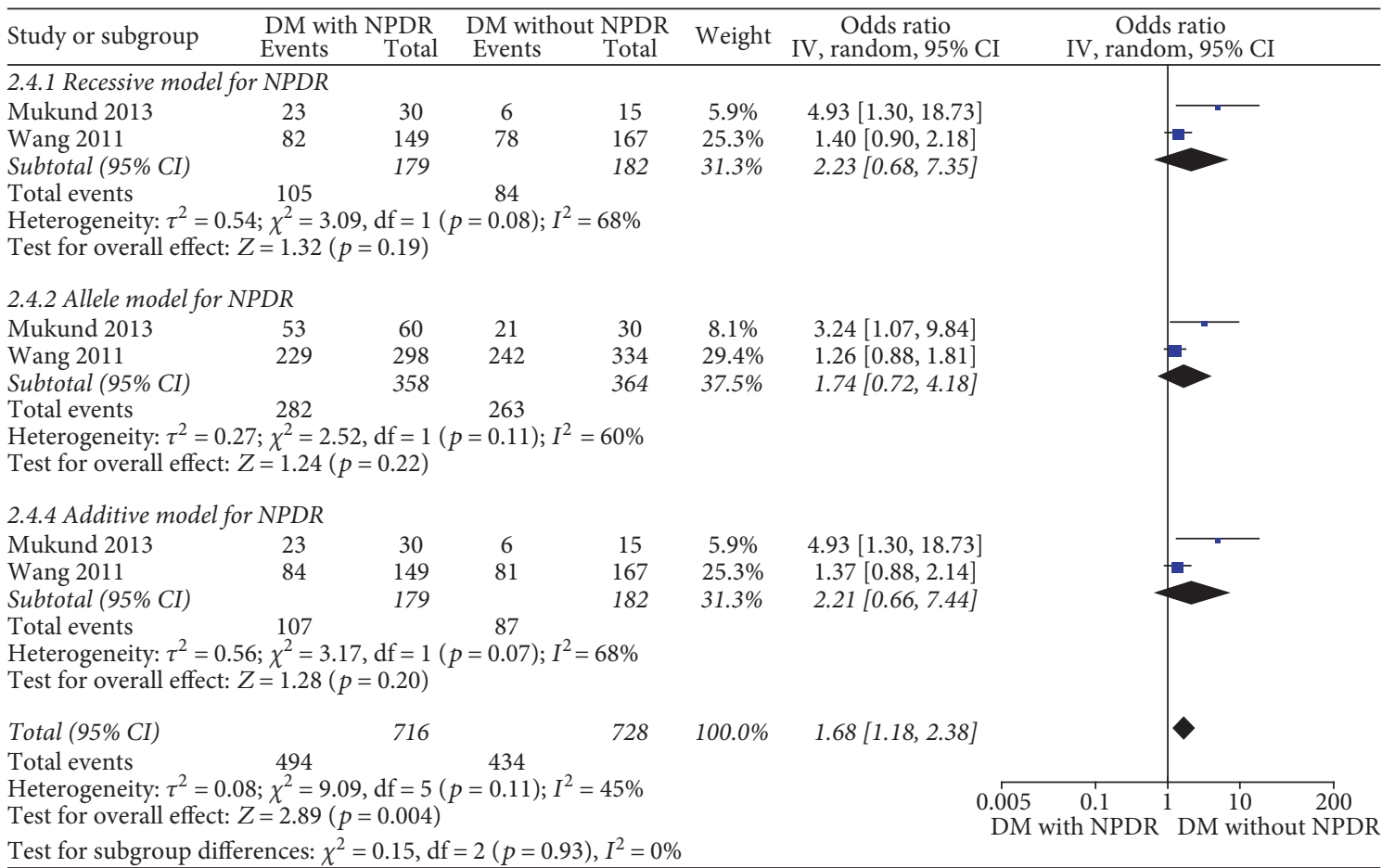

FIgURE 8: Forest plot for meta analysis comparing NPDR with DWR in different models.

3.2. The Association of Hp Gene Variants and DR. Four studies [15-18] in the dominant model comparing those DWR and DR patients showed great heterogeneity of the studies $\left(X^{2} p=0.01<0.05, I^{2}=73 \%\right)$; the total effect size OR in this study was 1.11 (95\% CI: $0.26,4.70)$, and the $Z$ value was $0.14(p>0.05)$, suggesting that $\mathrm{Hp}$ gene variants were not associated with DR (Figure 2). Similarly, the allelic model showed serious heterogeneity $\left(X^{2} p<0.05, I^{2}=86 \%\right)$; the total effect size OR in this study was 0.80 (95\% CI: 0.43 , $1.49)$, and the $Z$ value was $0.70(p>0.05)$, suggesting that no association was found between the Hp gene variants and DR (Figure 3). The recessive model also showed serious heterogeneity of the studies $\left(X^{2} p<0.05, I^{2}=82 \%\right)$; the total effect size OR and $Z$ value were 0.74 (95\% CI: $0.36,1.54)$ and $0.81(p>0.05)$, respectively, indicating that $\mathrm{Hp}$ gene variant was not associated with DR either (Figure 4). However, the heterozygote model showed no heterogeneity of the studies comparing DR and DWR $\left(X^{2} p=0.11>0.05\right.$, $\left.I^{2}=50 \%\right)$; the total effect size OR in this study was 2.39 (95\% CI: $1.17,4.87)$, and the $Z$ value was $2.39(p<0.05)$, suggesting that $\mathrm{Hp}$ gene variants were associated with $\mathrm{DR}$ (Figure 5). The homozygous and additive model showed serious heterogeneity of the studies $\left(I^{2}=74 \%\right.$ and $75 \%$, resp.), and the $Z$ value and the total effect size OR are both suggesting that $\mathrm{Hp}$ gene variants were not associated with DR (Figures 6 and 7).

3.3. The Association of Hp Gene Variants and NPDR. In this study, two studies $[13,14]$ in the recessive model, allele model, and additive model all showed no heterogeneity of the studies between DR and DWR $\left(X^{2} p=0.08\right.$, $I^{2}=68 \% ; X^{2} p=0.11, I^{2}=60 \% ;$ and $X^{2} p=0.07, I^{2}=68 \%$, resp.); the subtotal effect size $\mathrm{OR}$ in this study was 2.23 (95\% CI: 0.68, 7.35), 1.74 (95\% CI: 0.72, 4.18), and 2.21 


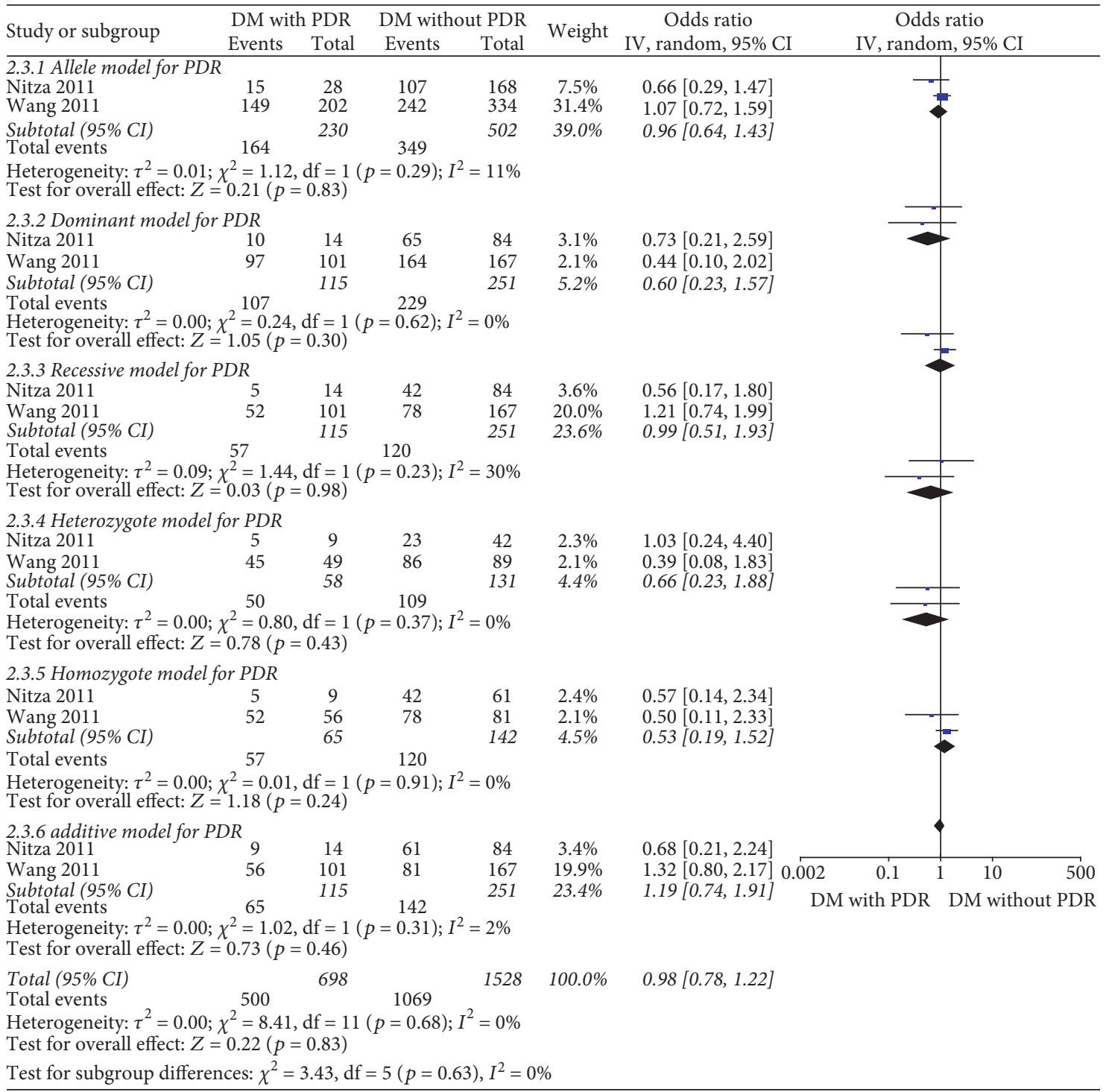

FIGURE 9: Forest plot for meta analysis comparing PDR with DWR in different models.

(95\% CI: 0.66, 7.44), respectively, all suggesting that $\mathrm{Hp}$ gene variants were not associated with NPDR (Figure 8). The heterozygote model and homozygous model were not suitable for the data; therefore, no results were obtained. However, the $p$ value of the overall effect $Z$ value from different models was less than 0.05 , indicating the association between $\mathrm{Hp}$ gene variants and NPDR.

3.4. The Association of HP Gene Variants and PDR. Two studies $[14,18]$ in all models showed no heterogeneity of the studies $\left(X^{2} p=0.29>0.1, I^{2}=11 \% ; X^{2} p=0.62>0.1\right.$, $I^{2}=0 \% ; \quad X^{2} p=0.23>0.1, \quad I^{2}=30 \% ; \quad X^{2} p=0.37>0.1$, $I^{2}=0 \% ; X^{2} p=0.91>0.1, I^{2}=0 \% ;$ and $X^{2} p=0.31>0.1$, $I^{2}=2 \%$ ), and the subtotal effect size OR in these studies was 0.96 (95\% CI: 0.64, 1.43), 0.60 (95\% CI: 0.23, 1.57), 0.99 (95\% CI: $0.51,1.93), 0.66$ (95\% CI: $0.23,1.88), 0.53$ (95\% CI: $0.19,1.52)$, and 1.19 (95\% CI: 0.74, 1.91), respectively, all suggesting that $\mathrm{Hp}$ gene variants were not associated with PDR (Figure 9).
Funnel plots of each group of meta-analysis were shown, and those funnel plots without outlines were due to the use of the random effect model (See Supplementary Figures S1-S8 available online at https://doi.org/ $10.1155 / 2017 / 2195059)$.

\section{Discussion}

The global incidence and prevalence of DM have increased significantly over the last several decades $[19,20]$. Patients with DM are often at a high risk of microvascular events $[21,22]$, in which DR is one of such risky events and might result in blindness at the late stage. The potential use of retinal vessel changes as a unique diagnostic biomarker for DR diagnosis is commonly investigated [23-25]. Recently, precision medicine idea empowers genetic codes as an early prediction tool for DR; therefore, we tried to analyze recent clinical studies on such possible gene candidates for DR prediction. Although several 
genome-wide association studies (GWAS) in different populations, such as Pima Indians [26, 27], MexicanAmericans [28], Asian [29-31], and Caucasians [32], identified multiple susceptibility loci to DR and reported evidence for the linkage of DR to several chromosomal regions, the susceptibility genes in these regions remain to be elucidated. Hp gene is one of such candidate genes and has been recently found to be related to vascular complications like retinopathy after diabetes since Hp-encoded protein is regarded as a positive acute phase reactant due to its binding capacity to hemoglobin ( $\mathrm{Hb})$ [33]. It has been figured out that free $\mathrm{Hb}$ is a relevant potent prooxidant which mediates several oxidative pathways resulting in the formation of hydroxyl radicals [34], which are often related to DM complications. $\mathrm{Hp}-\mathrm{Hb}$ binding could exert an anti-inflammatory effect by removing heme compounds which catalyze the oxidation of arachidonic acid by prostaglandin synthase. Interestingly, such $\mathrm{Hp}-\mathrm{Hb}$ binding capacity depends not only on serum $\mathrm{Hp}$ concentration but also on $\mathrm{Hp}$ phenotypes. Therefore, we investigated different Hp genotype variants and their association with DR complications. The recessive model, allele model, additive model, and homozygote model results showed that $\mathrm{Hp}$ gene variants were not associated with DR, NPDR, and PDR. However, the heterozygote model indicated the association of Hp gene variants with $\mathrm{DR}$. The heterozygote model is the case where the heterozygote conveys both advantages and disadvantages, while both homozygotes convey a disadvantage. A wellestablished case of heterozygote advantage is that of the gene involved in sickle cell anaemia. A recent study [35] has shown that low levels of nitric oxide (NO), a major mediator of vascular tone, are significantly more prevalent in $\mathrm{Hp} 2-2$ DM individuals. The major reason for the reduced bioavailability of NO in the plasma Hp2-2 DM individuals is due to increased plasma $\mathrm{Hb}$ in these individuals. It has been reported that the Hp1-1 protein clears $\mathrm{Hb}$ more quickly than the $\mathrm{Hp} 2-2$ protein, and so there is more $\mathrm{Hp} 2-2-\mathrm{Hb}$ available to bind to ApoA1 in Hp2-2 individuals [36]. As Hp genotype was indicated to be associated with $\mathrm{DR}$, there should be a tendency that such association should be consistent with the severity of the outcome in a dose-dependent manner, in our case, PDR. However, all models in our subgroup analysis showed no association between Hp gene variants and PDR. Nephropathy is usually regarded as one of the complications of T2DM at a serious stage and has been reported to be associated with PDR [37]. Nakhoul et al. reported the association between $\mathrm{Hp}$ gene and the risk of nephropathy [38]. However, such association was found to be not significant in Wobeto et al.'s study [39]; therefore, more studies are required to confirm the association between Hp genotype and severity of DR and the underlying mechanism is worth of investigation.

Meta-analysis is a comprehensive statistical method that has been used increasingly for combining and integrating data from a number of independent studies. However, the results of meta-analysis depend on the quality of primary researches included for further analysis. In this study, there are some limitations that might be affecting the summarized results. First, our studies included populations which are not from the same region and DM duration was not uniform in these research groups. Second, some publication bias could be attributed to the inaccuracy association between Hp gene and NPDR, therefore making its result not robust. Third, despite the relatively large size of the population from which cases were derived, the number of DR patients was relatively small. Furthermore, we had problems with missing data during data extraction in Hp1-1 phenotype subjects for NPDR, which have unpredictable effects on multivariate estimates on risk.

Despite the above-mentioned weaknesses, in the metaanalysis comparing DR with DWR, the heterozygote model indicated the association of $\mathrm{Hp}$ gene variants with DR. More primary large-sample and well-controlled studies on the association between $\mathrm{Hp}$ genotype variants and $\mathrm{DR}$ are required to verify these findings.

\section{Conflicts of Interest}

The authors declare no conflict of interest.

\section{Authors' Contributions}

Huiqun Wu and Huan Wu contributed equally to this work.

\section{Acknowledgments}

This work was supported by the grants from the National Natural Science Foundation of China (nos. 81501559 and 81371663), Natural Science Foundation of the Higher Education Institutions of Jiangsu Province (no. 15KJB310015), and Science and Technology Project of Nantong City (MS12015105), Jiangsu Overseas Research \& Training Program for University Prominent Young \& Middle-aged Teachers and Presidents 2016, Science and Technology Project Nantong University (15Z04), and Graduate Research and Innovation Plan Project of Nantong University (YKC15056).

\section{References}

[1] A. Chadli, S. El Aziz, N. El Ansari et al., "Management of diabetes in Morocco: results of the International Diabetes Management Practices Study (IDMPS) - wave 5," Therapeutic Advances in Endocrinology and Metabolism, vol. 7, pp. 101109, 2016.

[2] A. Phillips, "Optimising the person-centred management of type 2 diabetes," The British Journal of Nursing, vol. 25, pp. 535-538, 2016.

[3] M. F. Mahomoodally, A. Mootoosamy, and S. Wambugu, "Traditional therapies used to manage diabetes and related complications in Mauritius: a comparative ethnoreligious study," Evidence-Based Complementary and Alternative Medicine, vol. 2016, Article ID 4523828, 25 pages, 2016.

[4] J. A. Beckman and M. A. Creager, "Vascular complications of diabetes," Circulation Research, vol. 118, pp. 1771-1785, 2016.

[5] R. Klein and B. E. Klein, "Are individuals with diabetes seeing better? A long-term epidemiological perspective," Diabetes, vol. 59, pp. 1853-1860, 2010. 
[6] R. Klein, M. D. Knudtson, K. E. Lee, R. Gangnon, and B. E. Klein, "The Wisconsin epidemiologic study of diabetic retinopathy: XXII the twenty-five-year progression of retinopathy in persons with type 1 diabetes," Ophthalmology, vol. 115, pp. 1859-1868, 2008.

[7] E. J. Hollox and L. V. Wain, "Recurrent mutation at the classical haptoglobin structural polymorphism," Nature Genetics, vol. 48, no. 4, pp. 347-348, 2016.

[8] L. E. Cahill, M. K. Jensen, S. E. Chiuve et al., "The risk of coronary heart disease associated with glycosylated hemoglobin of $6.5 \%$ or greater is pronounced in the haptoglobin $2-2$ genotype," Journal of the American College of Cardiology, vol. 66, no. 16, pp. 1791-1799, 2015.

[9] Y. C. Chen, C. C. Lee, C. Y. Huang et al., "Haptoglobin polymorphism as a risk factor for chronic kidney disease: a case-control study," Amercican Journal of Nephrology, vol. 33, no. 6, pp. 510-514, 2011.

[10] J. Staals, B. M. Pieters, I. L. Knottnerus et al., "Haptoglobin polymorphism and lacunar stroke," Current Neurovascular Research, vol. 5, no. 3, pp. 153-158, 2008.

[11] A. A. Amiri, M. B. Hashemi-Soteh, M. R. Haghshenas, F. Daneshvar, A. Rastegar, and T. Farazmand, "Haptoglobin polymorphism in individuals with type 2 diabetic microangiopathy," North American Journal of Medical Sciences, vol. 5, pp. 529-535, 2013.

[12] R. Asleh and A. P. Levy, "In vivo and in vitro studies establishing haptoglobin as a major susceptibility gene for diabetic vascular disease," Vascular Health and Risk Management, vol. 1, pp. 19-28, 2005.

[13] M. H. Hampe and M. R. Mogarekar, "Haptoglobin2-2 phenotype is an additional risk factor of retinopathy in type 2 diabetes mellitus," Indian Journal of Human Genetics, vol. 19, pp. 154-158, 2013.

[14] G. C. Nitza, G. Merav, D. S. Olga et al., "Does haptoglobin genotype affect early onset of diabetic retinopathy in patients with type 2 diabetes?" Retina, vol. 31, pp. 15741580, 2011.

[15] M. B. Adinortey, B. A. Gyan, J. P. Adjimani et al., "Haptoglobin polymorphism and association with complications in Ghanaian type 2 diabetic patients," Indian Journal of Clinical Biochemistry, vol. 26, pp. 366-372, 2011.

[16] V. P. Wobeto, E. T. Rosim, M. B. Melo, L. E. Calliari, and F. Sonati Mde, "Haptoglobin polymorphism and diabetic retinopathy in Brazilian patients," Diabetes Research and Clinical Practice, vol. 77, pp. 385-388, 2007.

[17] S. Y. Meng, S. Chen, D. Q. Li, P. Yu, S. J. Zhou, and D. M. Yu, "Association of haptoglobin gene polymorphism with diabetic retinopathy in type 2 diabetes mellitus (A)," Chinese Journal of Diabetes, vol. 19, pp. 325-327, 2011.

[18] J. J. Wang, S. Chen, P. Yu, S. Y. Meng, S. J. Zhou, and D. M. Yu, "Association of haptoglobin gene polymorphism with diabetic retinopathy in type 2 diabetes mellitus (B)," Chinese Journal of Diabetes, vol. 19, pp. 329-332, 2011.

[19] T. M. Abraham, K. M. Pencina, M. J. Pencina, and C. S. Fox, "Trends in diabetes incidence: the Framingham Heart Study," Diabetes Care, vol. 38, pp. 482-487, 2015.

[20] L. S. Geiss, J. Wang, Y. J. Cheng et al., "Prevalence and incidence trends for diagnosed diabetes among adults aged 20 to 79 years, United States, 1980-2012," JAMA, vol. 312, pp. 1218-1226, 2014.
[21] Y. W. Chen, Y. Y. Wang, D. Zhao et al., "High prevalence of lower extremity peripheral artery disease in type 2 diabetes patients with proliferative diabetic retinopathy," PloS One, vol. 10, no. 3, article e0122022, 2015.

[22] J. M. Tarr, K. Kaul, M. Chopra, E. M. Kohner, and R. Chibber, "Pathophysiology of diabetic retinopathy," ISRN Ophthalmology, vol. 2013, Article ID 343560, 13 pages, 2013.

[23] H. Kan, J. Stevens, G. Heiss, R. Klein, K. M. Rose, and S. J. London, "Dietary fiber intake and retinal vascular caliber in the atherosclerosis risk in communities study," The American Journal of Clinical Nutrition, vol. 86, pp. 1626-1632, 2007.

[24] L. Wang, T. Y. Wong, A. R. Sharrett, R. Klein, A. R. Folsom, and M. Jerosch-Herold, "Relationship between retinal arteriolar narrowing and myocardial perfusion: multi-ethnic study of atherosclerosis," Hypertension, vol. 51, pp. 119-126, 2008.

[25] N. Cheung, F. M. Islam, D. R. Jacobs Jr et al., "Arterial compliance and retinal vascular caliber in cerebrovascular disease," Annals of Neurology, vol. 62, pp. 618-624, 2007.

[26] G. Imperatore, R. L. Hanson, D. J. Pettitt, S. Kobes, P. H. Bennett, and W. C. Knowler, "Sib-pair linkage analysis for susceptibility genes for microvascular complications among Pima Indians with type 2 diabetes. Pima diabetes genes group," Diabetes, vol. 47, pp. 821-830, 1998.

[27] H. C. Looker, R. G. Nelson, E. Chew et al., "Genome-wide linkage analyses to identify loci for diabetic retinopathy," Diabetes, vol. 56, pp. 1160-1166, 2007.

[28] Y. P. Fu, D. M. Hallman, V. H. Gonzalez et al., "Identification of diabetic retinopathy genes through a genome-wide association study among Mexican-Americans from Starr County, Texas," Journal of Ophthalmology, vol. 2010, 2010.

[29] Y. C. Huang, J. M. Lin, H. J. Lin et al., "Genome-wide association study of diabetic retinopathy in a Taiwanese population," Ophthalmology, vol. 118, pp. 642-648, 2011.

[30] T. Awata, H. Yamashita, S. Kurihara et al., "A genome-wide association study for diabetic retinopathy in a Japanese population: potential association with a long intergenic non-coding RNA," PloS One, vol. 9, no. 11, article e111715, 2014.

[31] W. H. Sheu, J. Z. Kuo, I. T. Lee et al., "Genome-wide association study in a Chinese population with diabetic retinopathy," Human Molecular Genetics, vol. 22, pp. 3165-3173, 2013.

[32] M. A. Grassi, A. Tikhomirov, S. Ramalingam, J. E. Below, N. J. Cox, and D. L. Nicolae, "Genome-wide meta-analysis for severe diabetic retinopathy," Human Molecular Genetics, vol. 20, pp. 2472-2481, 2011.

[33] M. MacKellar and D. J. Vigerust, "Role of haptoglobin in health and disease: a focus on diabetes," Clinical Diabetes, vol. 34, no. 3, pp. 148-157, 2016.

[34] M. J. Nielsen and S. K. Moestrup, "Receptor targeting of hemoglobin mediated by the haptoglobins: roles beyond heme scavenging," Blood, vol. 114, pp. 764-771, 2009.

[35] I. Dahan, E. Farber, N. Thauho et al., "Interaction between the haptoglobin 2 phenotype and diabetes mellitus on systolic pulmonary arterial pressure and nitric oxide bioavailability in hemodialysis patients," Journal of Diabetes Research, vol. 2015, Article ID 613860, 7 pages, 2015.

[36] J. Watanabe, V. Grijalva, S. Hama et al., "Hemoglobin and its scavenger protein haptoglobin associate with ApoA-1-containing particles and influence the inflammatory properties and function of high density lipoprotein," The Journal of Biological Chemistry, vol. 284, no. 27, pp. 18292-18301, 2009. 
[37] M. C. Boelter, J. L. Gross, L. H. Canani et al., "Proliferative diabetic retinopathy is associated with microalbuminuria in patients with type 2 diabetes," Brazilian Journal of Medical and Biological Research, vol. 39, no. 8, pp. 1033-1039, 2006.

[38] F. M. Nakhoul, R. Miller-Lotan, H. Awaad, R. Asleh, and A. P. Levy, "Hypothesis-haptoglobin genotype and diabetic nephropathy," Nature Clinical Practice Nephrology, vol. 3, pp. 339-344, 2007.

[39] V. P. Wobeto, P. M. Garcia, T. R. Zaccariotto, and F. Sonati Mde, "Haptoglobin polymorphism and diabetic nephropathy in Brazilian diabetic patients," Annals of Human Biology, vol. 36, pp. 437-441, 2009. 


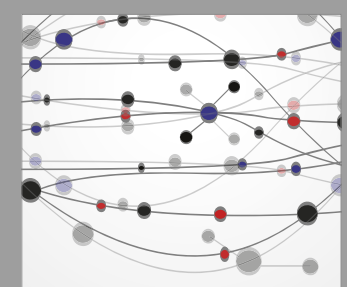

The Scientific World Journal
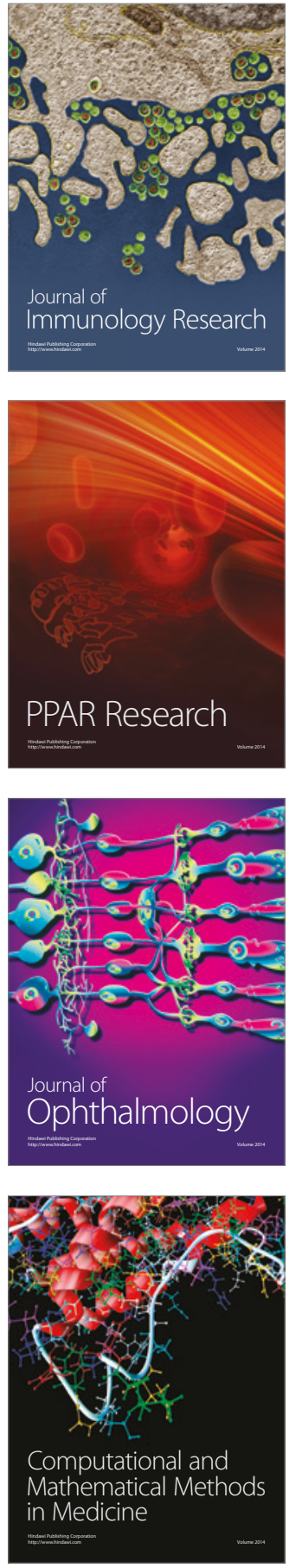

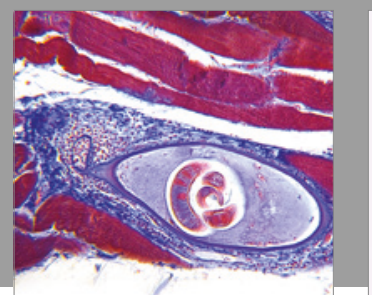

Gastroenterology Research and Practice
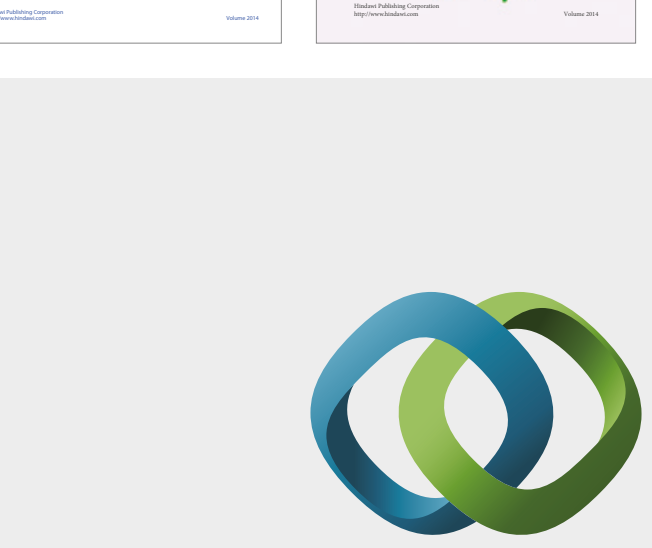

\section{Hindawi}

Submit your manuscripts at

https://www.hindawi.com
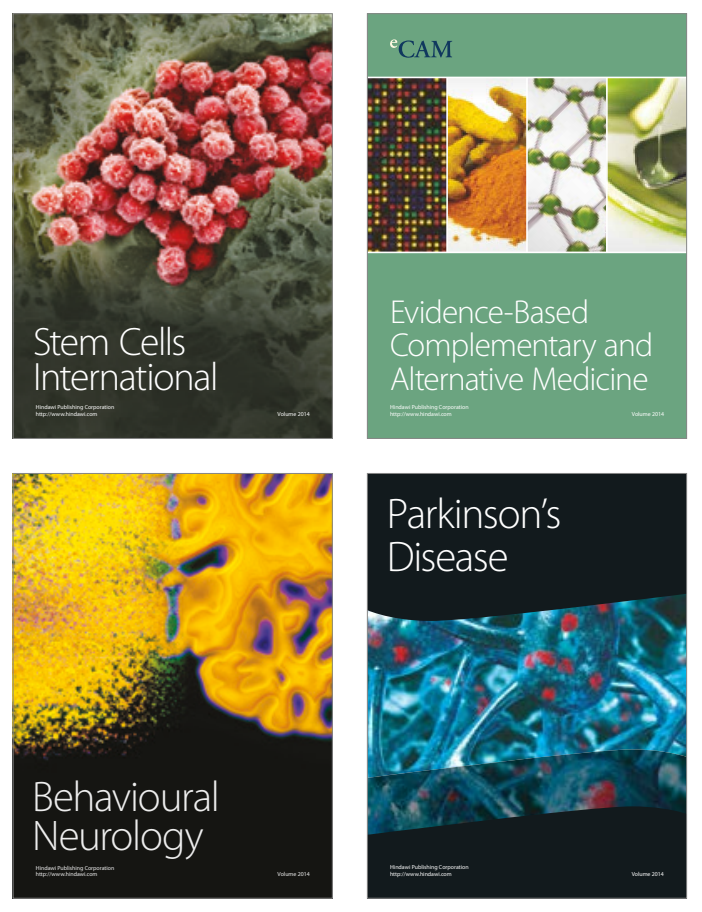
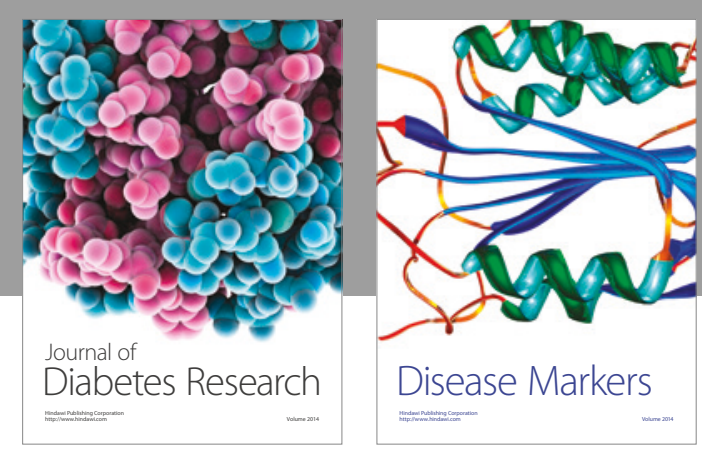

Disease Markers
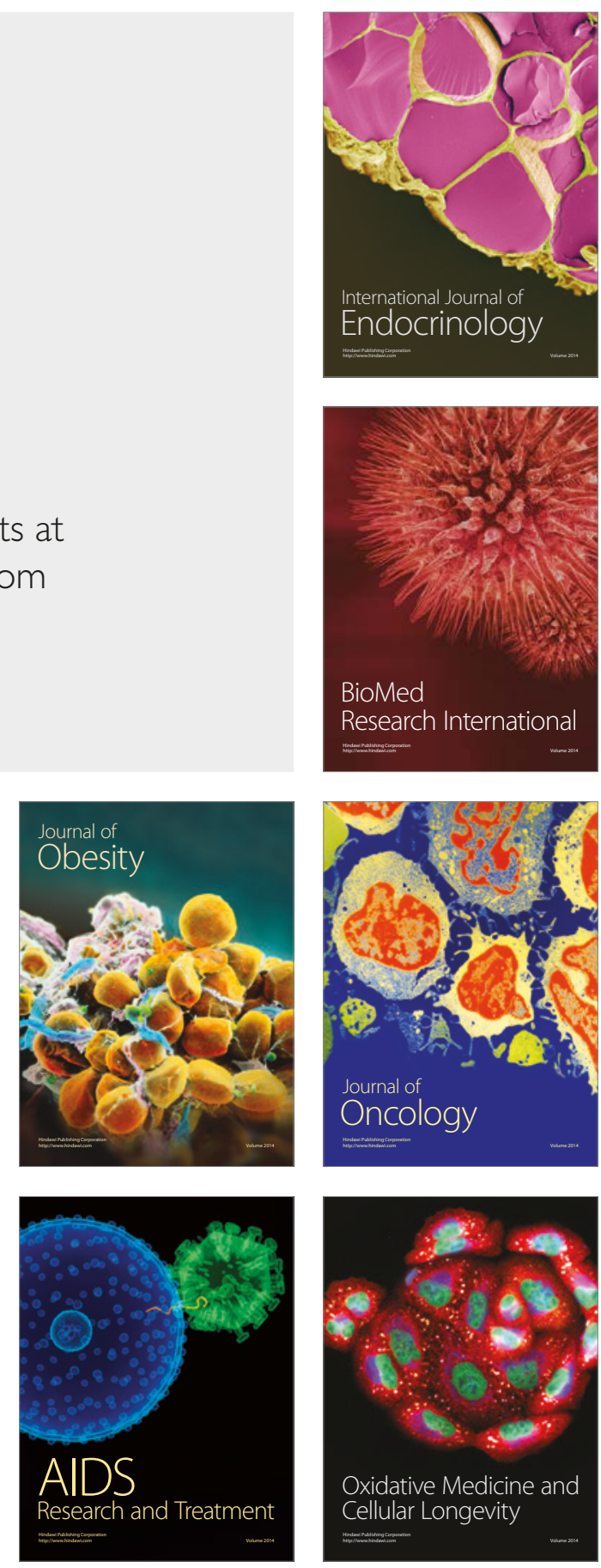